\title{
Epidemiological and Clinical Characteristics and Outcomes of Scorpion Envenomation in Hospitalized Children in Adiyaman, Turkey
}

\author{
Capan Konca ${ }^{1, *}$; Mehmet Tekin ${ }^{1}$; Yeliz Genc ${ }^{1}$; Mehmet Turgut ${ }^{1}$ \\ ${ }^{1}$ Department of Pediatrics, School of Medicine, Adiyaman University, Adiyaman, Turkey \\ ${ }^{*}$ Corresponding author: Capan Konca, Department of Pediatrics, School of Medicine, Adiyaman University, Adiyaman, Turkey. Tel: +90-5054896904, Fax: +90-4162252660, E-mail: \\ dr.capan@hotmail.com
}

Received:January 6, 2014; Accepted: December 13, 2014

Keywords: Children; Scorpion Envenomation; Outcome; Hospitalized

Scorpion envenomation is a public health problem in tropical and subtropical countries. The majority of scorpion sting cases present with local pain at the site of sting and follow a benign clinical course. Severe intoxication may include cardiac and respiratory dysfunction, leading to multi-system organ failure and death (1, 2 ). The deaths in scorpion sting envenomation (SE) are attributed to cardiopulmonary complications, such as myocarditis and acute pulmonary edema (3).

Cases of SE are common in Turkey, especially in Southeast Anatolia, owing to its geographical location, climate and socioeconomic structure (4). However, there is a scarcity of epidemiologic data on SE in Turkey because of the underdeclaration of scorpion sting cases and paucity of studies on the subject. Therefore, this study aims to evaluate the children hospitalized owing to scorpion stings and their epidemiological and clinical characteristics in Adiyaman province.

Medical records of 80 patients were retrospectively reviewed to collect the following data: age, gender, clinical symptoms (localized and systemic), vital signs, information about the date and place of the sting occurrence, anatomical sting site, time elapsed between the sting and arrival at the hospital, type of scorpion, severity of the patients' symptoms, treatment modalities and outcomes. The diagnosis of SE was based on the history of scorpion sting. The scorpion type was identified based on the colour of the scorpion defined by the patient or bystander. A. crassicauda and M. eupeus are more commonly known as the black and yellow scorpions, respectively (4). Patients were classified into three classes according to clinical severity as follows: class I: local manifestations; class II: systemic involvement; and class III: cardiovascular, respiratory or neurological symptoms (such as cardiogenic shock, pulmonary edema, altered consciousness and convulsive crisis) (5). A total of 80 subjects were recruited for this study. Of these, 42 (52.5\%) were male and 38 (47.5\%) female, with a mean age of $6.5 \pm 4.1$ years (range: 6 months to 17 years). Moreover, 51 (63.7\%) and 29 (36.3\%) of these subjects were from rural and urban areas, respectively. In terms of the type of scorpion, 32 (40\%) subjects were stung by black scorpions and 27 (33.7\%) by yellow scorpions. In 13 (16.3\%) cases, the patients could not identify the colour of the scorpions. The most common sting sites were lower extremity $(n=53,66.2 \%)$, upper extremity $(n=17,21.2 \%)$ and body $(n=7,8.8 \%)$. The patients were mostly stung during the day (57.5\%). The average time elapsed between being stung and admitted in the hospital was $100.3 \pm 106.5$ minutes (range: 20 to 490 minutes). Based on clinical severity, 34 (42.5\%), 44 (55\%) and 2 (2.5\%) patients were classified into classes I, II, and III, respectively. Table 1 presents the demographic and epidemiological characteristics of the subjects.

The majority of the cases (63.7\%) were reported during summer. The monthly distribution of scorpion sting cases was as follows: $11.2 \%$ in May, $13.7 \%$ in June, $27.5 \%$ in July, 22.5\% in August and 10\% in September; this indicates that the number of scorpion sting cases peaked in July.

Patients exhibited both local and systemic effects. The most common local symptoms were pain $(n=71,88.7 \%)$, hyperemia $(n=43,53.7 \%)$ and swelling $(n=23,28.7 \%)$. The most common systemic symptoms included cold extremities (50\%), pallor (16.2\%), hypotension (7.5\%), hypertension (7.5\%), sweating (6.2\%) and dry mouth (6.2\%). The most common laboratory findings were high the most common laboratory findings were high lactate dehydrogenase $(\mathrm{LDH})(\mathrm{n}=10)$, creatine phosphokinase (CPK) $(n=9)$, Aspartat aminotransferase (AST) $(n=2)$ and Alanine aminotransferase (ALT) $(n=2)$ levels. Leucocytosis was present in $9(11.2 \%)$ cases and hypoglycaemia was observed in 1 (1.2\%) case. An electrocardiogram (ECG) was conducted for all the patients. The most common electrocardiography sign was tachycardia (30\%). Other

Copyright (C) 2015, Growth \& Development Research Center. This is an open-access article distributed under the terms of the Creative Commons Attribution-NonCommercial 4.0 International License (http://creativecommons.org/licenses/by-nc/4.0/) which permits copy and redistribute the material just in noncommercial usages, provided the original work is properly cited. 
Table 1. Demographic and Epidemiological Characteristics of Patients ${ }^{\text {a }}$

\begin{tabular}{lc}
\hline Characteristics & values \\
\hline Sex & \\
\hline Female & $38(47.5)$ \\
\hline Male & $42(52.5)$ \\
Scorpion identification & \\
\hline Black & $32(40.0)$ \\
\hline Yellow & $27(33.7)$ \\
\hline Others & $8(10.0)$ \\
\hline Unknown & $13(16.3)$ \\
\hline Sting site & \\
\hline Lower extremity & $53(66.2)$ \\
\hline Upper extremity & $17(21.2)$ \\
\hline Body & $7(8.8)$ \\
\hline Head and neck & $3(3.8)$ \\
\hline District & \\
\hline Rural & $51(63.7)$ \\
\hline Urban & $29(36.3)$ \\
\hline Time of sting & \\
\hline Night & $34(42.5)$ \\
\hline Day & $46(57.5)$ \\
\hline Cnvenomation severity & \\
\hline Class II & $34(42.5)$ \\
\hline Class III & $44(55.0)$ \\
\hline Recovery & $2(2.5)$ \\
\hline Death & \\
\hline Data are presented as No.(\%). & \\
\hline
\end{tabular}

ECG abnormalities were ST alterations $(n=5,6.2 \%)$ and prolonged QT ( $n=6,7.5 \%)$. Table 2 presents the patients' clinical and laboratory features.

One $5 \mathrm{~mL}$ dose of scorpion polyvalent antivenom ampoule, steroid and antihistaminic, was administered to all the patients in emergency services before they were admitted to the hospital. The second antivenom application and a five-step treatment plan, which was suggested by Bawaskar (6), were administered based on the clinical findings in PICU. Before discharge, all the participants were immunized for tetanus. The mean hospitalization time was $2.1 \pm 1.4$ days (range: 6 hours to 6 days). Except for the one case, all other patients $(n=79)$ were discharged after recovery. The one patient (1.2\%) who had died of cardiac and respiratory arrest manifested evidence of severe envenomation.

In conclusion, this study reported on the epidemiological and clinical characteristics of scorpion poisoning in Adiyaman, Turkey during a one-year period. Although males were found to be more susceptible to scorpion stings than females, the difference was not statistically significant. The age of the majority of the scorpion sting victims was less than 10 years. The majority of scorpion stings occurred during daytime. The most common sting sites were the distal part of the extremities. The results of this study showed that intoxications caused by scorpions in Southeast Anatolia region mostly occurred in the summer months, especially July and August. Scorpionism in Adiyaman is essentially caused by two species of scorpions: A. crassicauda and M. eupeus. Both local and systemic effects were observed in clinical evaluations. The results of our study supported that although systemic toxicity signs due to scorpion stings appear frequently, life-threatening signs are rare. To decrease morbidity and mortality rates, patients should be monitored in PICU with an early and appropriate treatment approach.

\begin{tabular}{|c|c|}
\hline Clinical and laboratory Features & values \\
\hline \multicolumn{2}{|l|}{ Local sign } \\
\hline Pain & $71(88.7)$ \\
\hline Hyperemia & $43(53.7)$ \\
\hline Swelling & $23(28.7)$ \\
\hline \multicolumn{2}{|l|}{ Systemic sign } \\
\hline Cold extremities & $40(50.0)$ \\
\hline Pallor & $13(16.2)$ \\
\hline Hypotension & $6(7.5)$ \\
\hline Hypertension & $6(7.5)$ \\
\hline Sweating & $5(6.2)$ \\
\hline Dry mouth & $5(6.2)$ \\
\hline Tachycardia & $4(5.0)$ \\
\hline Womiting & $3(3.7)$ \\
\hline Pulmonary edema & $2(2.5)$ \\
\hline Myocarditis & $2(2.5)$ \\
\hline \multicolumn{2}{|l|}{ Laboratory findings } \\
\hline High LDH & $10(12.5)$ \\
\hline High CK & $9(11.2)$ \\
\hline Leukocytosis & $9(11.2)$ \\
\hline High AST/ALT & $2(2.5)$ \\
\hline Hypoglisemia & $1(1.2)$ \\
\hline \multicolumn{2}{|l|}{ Treatment } \\
\hline Antivenom therapy & $80(100.0)$ \\
\hline Antihistamines & $80(100.0)$ \\
\hline Steroids & $80(100.0)$ \\
\hline Intravenous hydration & $73(91.2)$ \\
\hline Analgesia & $73(91.2)$ \\
\hline Doxazosin & $46(57.5)$ \\
\hline Antibotic & $27(33.7)$ \\
\hline Dobutamine & $2(2.5)$ \\
\hline Mechanical ventilation & $2(2.5)$ \\
\hline
\end{tabular}




\section{References}

1. Dittrich K, Ahmed R, Ahmed QA. Cardiac arrest following scorpion envenomation. Ann Saudi Med. 2002;22(1-2):87-90.

2. Tarasiuk A, Khvatskin S, Sofer S. Effects of antivenom serotherapy on hemodynamic pathophysiology in dogs injected with L. quinquestriatus scorpion venom. Toxicon. 1998;36(7):963-71.

3. Guerra CM, Carvalho LF, Colosimo EA, Freire HB. Analysis of variables related to fatal outcomes of scorpion envenomation in children and adolescents in the state of Minas Gerais, Brazil, from 2001 to 2005.J Pediatr (Rio J). 2008;84(6):509-15.

4. Ozkan O, Adiguzel S, Yakistiran S, Cesaretli Y, Orman M, Karaer KZ. Androctonus crassicauda (Olivier 1807) scorpionism in the Sanliurfa provinces of Turkey. Turkiye Parazitol Derg. 2006;30(3):239-45.

5. Khattabi A, Soulaymani-Bencheikh R, Achour S, Salmi LR, Scorpion Consensus Expert G. Classification of clinical consequences of scorpion stings: consensus development. Trans R Soc Trop Med Hyg. 2011;105(7):364-9.

6. Bawaskar HS, Bawaskar PH. Scorpion sting: update. J Assoc Physicians India. 2012;60:46-55. 